\title{
Antibiotic Inhibition and Binding Studies with a Group A Streptococcal L-Form
}

\author{
By C. PANOS, M. COHEN AND GERALDINE FAGAN \\ Department of Biochemistry, Albert Einstein Medical Centre, \\ Northern Division, Philadelphia, Pennsylvania, U.S.A.
}

(Accepted for publication 13 September 1966)

\begin{abstract}
SUMMARY
The minimal inhibitory concentrations of various antibiotics for a strain of Streptococcus pyogenes and a stable L-form of it were determined. These results were evaluated with those of other investigators similarly performed with $S$. faecalis and derived protoplasts. Differences in reaction to puromycin, bacitracin and ristocetin were apparent only between the wall-less derivatives. The polyene antibiotics nystatin and filipin and two antimicrobial agents, isatin 3-thiosemicarbazone and 1-methyl-isatin 3-thiosemicarbazone, were ineffective or only slightly inhibitory on growth of $S$. pyogenes and its L-form. Labelled penicillin studies with this group A streptococcus and its L-form indicated that the binding sites for penicillin were probably distinct from those concerned with streptococcal wall formation.
\end{abstract}

\section{INTRODUCTION}

Some information is available about the sensitivity of bacteria and their derived L-forms or protoplasts to various antibiotics (Ward, Madoff \& Dienes, 1958; Shockman \& Lampen, 1962; Williams, 1963; Molander et al. 1964; Kagan, Zolla, Busser \& Liepnieks, 1964). The mode of action of such antimicrobial agents examined thus far has ranged from inhibition or disruption of a specific anatomical component (e.g. cell wall, membrane) to cessation of an essential metabolic process, e.g. protein synthesis. Although several antibiotics are known inhibitors of bacterial cell-wall biosynthesis, only penicillin and D-cycloserine (Krawitt \& Ward, 1963) and bacitracin (Rotta, Karakawa \& Krause, 1965) have been found capable of inducing ' $L$-phase variant' formation. The present work confirms the earlier results of others with certain group A streptococci (Ward et al. 1958; Rotta et al. 1965), staphylococci (Williams, 1963; Krawitt \& Ward, 1963; Kagan et al. 1964; Molander et al. 1964) and their respective L-forms and expands upon these comparisons. The affinity for penicillin of the L-form and its parent group A streptococcus, $S$. pyogenes, with regard to the inability of the $\mathrm{L}$-form to synthesize the rigid cell wall is discussed.

\section{METHODS}

The Streptococcus pyogenes and its derived stable L-form were the same as those used earlier (Panos, 1965). The L-form was grown in the absence of penicillin, otherwise the liquid medium used for each was as described previously (Panos \& Barkulis 1959). For the present work, medium (100 ml.) in $250 \mathrm{ml}$. Erlenmeyer flasks equipped 
with side-arm tubes were inoculated with 5 and $10 \mathrm{ml}$. overnight cultures, respectively, of the coccus or L-form. Each organism was grown at $35-36^{\circ}$ until extinction values of 0.200 and $0.280-0.300$ were attained by the L-form and parent streptococcus respectively, (approximately the middle of logarithmic growth), before addition of antibiotic. Changes in turbidity were followed at intervals with a Coleman model 14 spectrophotometer at $650 \mathrm{~m} \mu$. Uninoculated media served as blanks. Turbidity increase (growth) is due to an increase in viable numbers for this streptococcal L-form (Panos, 1965). Only logarithmic streptococcal and $\mathrm{L}$-form cultures whose growth rates (doublings/hr) were close to $1 \cdot 1$ and $0 \cdot 7$, respectively, were used. Each antibiotic was assayed at least four different times with each organism. Testing of possible salt effects was done by comparable studies with the coccus grown in L-form medium (containing $\mathrm{NaCl} 3 \%$, w/v). Unless specified otherwise, all antibiotics were dissolved in sterile water just before use. Most of these antimicrobial agents were obtained from Dr G. Shockman (Temple University, School of Medicine) and had been used in similar earlier studies (Shockman \& Lampen, 1962). Originally, they had been obtained from the sources indicated on request for the purest material available: actinomycin $D$ (free base, $99 \%$ pure) and novobiocin (sodium salt, lot no. L571789-2-4) and bacitracin (zinc salt, lot no. L474789-0-17) from Merck Sharp and Dohme Research Laboratories, Rahway, N.J.; cycloserine (free base, potency $1000 \mu \mathrm{g} . / \mathrm{mg}$.) and vancomycin (free base, potency $966 \mu \mathrm{g} . / \mathrm{ml}$.) from Eli Lilly Co., Indianapolis, Indiana; chloramphenicol (free base, $98.6 \%$ pure) and penicillin G (potassium salt) from Parke Davis and Co., Ann Arbor, Michigan; polymixin B (sulphate, potency $7000 \mathrm{U} . / \mathrm{mg}$.) from Burroughs Wellcome and Co., Tuckahoe, N.Y.; puromycin (free base, lot no. 7-5402) from Lederle Laboratories, Pearl River, N.Y.; and ristocetin (free base, potency $1000 \mu \mathrm{g} . / \mathrm{ml}$.) from Abbott Laboratories, Chicago, Illinois. Filipin (free base, potency $1000 \mu \mathrm{g} . / \mathrm{mg}$.; Upjohn Co., Kalamazoo, Michigan) and nystatin (free base, potency > 4000 U./mg.; Squibb Institute for Medical Research, New Brunswick, N.J.) were also assayed. Samples of isatin 3-thiosemicarbazone and 1-methylisatin 3-thiosemicarbazone were a gift from Dr D. J. Bauer, Wellcome Laboratories of Tropical Medicine, London, England. The concentrations given (Table 1) refer to the antibiotics as received. The criteria for growth inhibition and method of expression are similar to those used by Shockman \& Lampen (1962), as noted in the legend of Table 1.

For the determination of penicillin binding, a freshly prepared solution $(0.6 \mathrm{mg}$. $)$ ml.) of tritium-labelled benzyl-T(G) penicillin (Radiochemical Centre, Amersham, Buckinghamshire, England), specific activity of $128 \mathrm{mc} . / \mathrm{m}$-mole, was added $(20 \mu \mathrm{l}$.) to coccal and L-form cultures upon reaching an extinction of $0 \cdot 200$. Identical amounts of non-labelled crystalline penicillin-G were added to duplicate flasks as controls. Growth inhibition of only the parent coccus was observed after $1 \mathrm{hr}$, at which time $200 \mathrm{mg}$. non-labelled penicillin-G was added to all flasks. After an additional $15 \mathrm{~min}$., $20 \mu \mathrm{l}$. solution of tritium-labelled penicillin- $\mathrm{G}$ was added to those flasks containing only non-labelled penicillin; i.e. non-labelled + labelled penicillin (Table 2). All organisms were harvested after $15 \mathrm{~min}$. by centrifugation in a Serval centrifuge (4C) at $14,500 \mathrm{~g}$ for $10 \mathrm{~min}$. Each pellet was washed twice with $10 \mathrm{ml}$. distilled water or $3 \%(\mathrm{w} / \mathrm{v})$ sodium chloride solution for the coccus and L-form, respectively. Organisms were extracted with $10 \mathrm{ml} .0 .4 \mathrm{M}$-perchloric acid, centrifuged down and the pellets washed twice more as before. Distilled water $(0.35 \mathrm{ml}$.) was added to each pellet and samples 
collected by suction on tared cellulose acetate filter discs (Millipore Corp., Mass.) of pore size $0.45 \mu$, dried with an infrared lamp, and weighed. Filter discs were dried to constant weight before and after collection of samples and all weighings were done on an analytical microbalance. Radioactivity was determined with a Tricarb liquid scintillation spectrometer after placing each disc in $10 \mathrm{ml}$. of a counting solution [15.2 g. 2,5-diphenyloxazole (PPO) $+380 \mathrm{mg}$. 1,4-bis-2-(4-methyl-5-phenyloxazolyl)benzene (dimethyl POPOP) in 3.81 . toluene]. A specific activity for labelled penicillin was similarly obtained by depositing known quantities on discs, drying and counting as done for the samples. From the specific activity of the penicillin and the dry weight of organisms used, the amount of penicillin bound per g. of organism was calculated.

Table 1. Antibiotic inhibition of growth of Streptococcus pyogenes and its $L$-form

Minimal inhibitory concentration ( $\mu \mathrm{g} . / \mathrm{ml}$.$) medium*$

\begin{tabular}{|c|c|c|c|}
\hline & Streptococcus & L-form & $\begin{array}{l}\text { Streptococcus in } \\
\mathbf{L} \text {-form medium }\end{array}$ \\
\hline Actinomycin D & 0.2 & 0.05 & n.d. \\
\hline Bacitracin & 5 & $>300 \dagger$ & 5 \\
\hline Chloramphenicol & 3 & 3 & 3 \\
\hline Cycloserine & 240 & $>300$ & n.d. \\
\hline Novobiocin & 2 & 30 & 75 \\
\hline Penicillin G & 0.06 & $>300$ & n.d. \\
\hline Polymixin B & 240 & 300 & n.d. \\
\hline Puromycin & 30 & $2 \cdot 5-25 t$ & nd \\
\hline Ristocetin & 1 & $>300$ & $2-2 \cdot 5$ \\
\hline Vancomycin & $1 \cdot 5-2$ & $>300$ & 2 \\
\hline
\end{tabular}

RESULTS

Table 1 tabulates the minimal inhibitory concentrations of those antibiotics found capable of producing at least $50 \%$ inhibition of growth. Figure 1 illustrates a typical example of L-form growth, inhibition (polymixin B) and lysis (puromycin). As is apparent bacitracin, cycloserine, penicillin-G, ristocetin and vancomycin were ineffective in inhibiting L-form growth; this was expected since their primary site of action is purported to be inhibition of cell wall synthesis. Puromycin proved unusual in that above a minimal growth inhibitory concentration of $2.5 \mu \mathrm{g}$. $/ \mathrm{ml}$. medium, lysis of this L-form usually occurred (Fig. 1); the lysis was confirmed by phase microscopy. The time of initiation of lysis, however, varied from 35 to 110 min. after addition of puromycin. A similar but lesser lytic effect was also noted with novobiocin. However, under the conditions of assay, novobiocin was apparently affected by the sodium chloride content ( $3 \%, \mathrm{w} / \mathrm{v}$ ) of the $\mathrm{L}$-form medium (Table 1). Polymixin $\mathrm{B}$, known to denature microbial membranes, was inhibitory for the parent coccus and for its L-form only at high concentrations. Two polyene antibiotics, nystatin and filipin ( 215 and $150 \mu \mathrm{g} . / \mathrm{ml}$. medium, respectively), solubilized with the aid of tolerable amounts of redistilled dimethylsulfoxide (DMS $3-4 \%, v / v$ ), before addition to media, were either ineffective or only slightly inhibitory of the growth of the L-form and the 
parent coccus. Nystatin was without effect upon either organism. Filipin inhibited the growth only of the L-form, and that by $20 \%$, as compared with cultures containing DMS as controls. Two other antimicrobial agents, isatin 3-thiosemicarbazone and 1-methyl-isatin-3-thiosemicarbazone (effective in the prophylaxis of smallpox) were examined. A DMS solution of isatin 3-thiosemicarbazone was added $(80 \mu \mathrm{g} . / \mathrm{ml}$.) to the media with some effect, namely 14 and $25 \%$ growth inhibition for the coccus

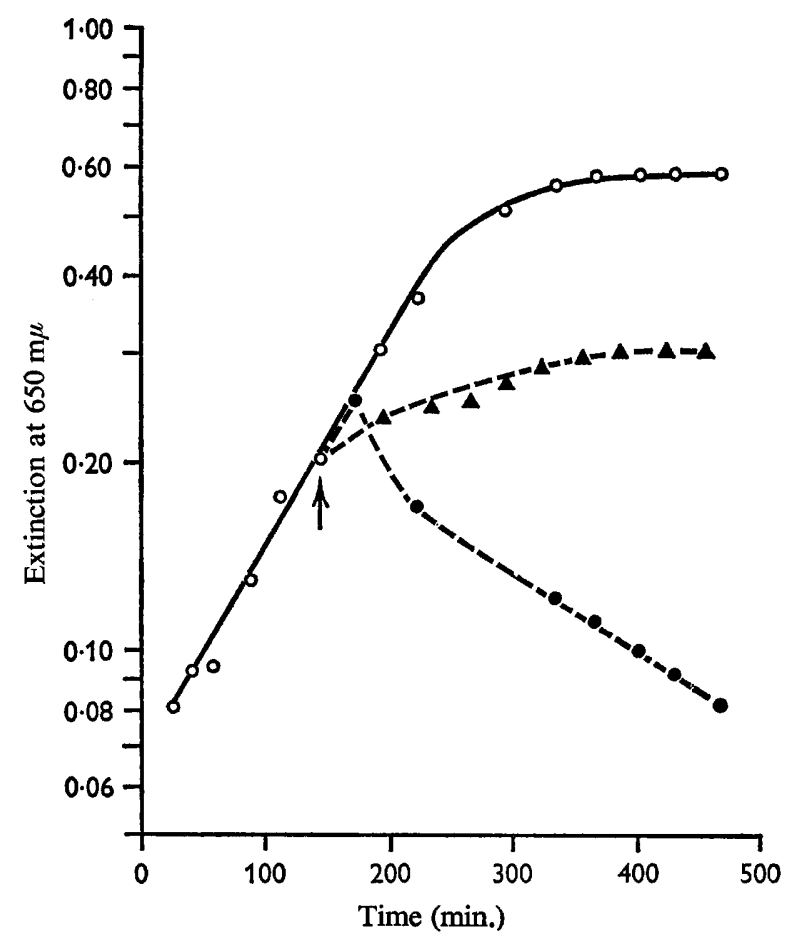

Fig. 1. Growth, inhibition and lysis of a stable L-form from Streptococcus pyogenes. $\mathrm{O}-\mathrm{O}$, no addition; $\boldsymbol{\Delta}-\mathbf{\Delta}$, polymixin $\mathbf{B}, 300 \mu \mathrm{g} . / \mathrm{ml}$. culture; -0, puromycin, $15 \mu \mathrm{g} . / \mathrm{ml}$. culture. Antibiotics added at point indicated by arrow.

Table 2. Tritium-labelled benzyl-T(G) penicillin binding by Streptococcus pyogenes and its stable L-form

Average of six determinations; L-form cultured in absence of penicillin.

$\begin{array}{lcc} & \begin{array}{c}\text { Penicillin bound } \\ (\mu \mathrm{g} . / \mathrm{g} . \text { organism) }\end{array} & \begin{array}{c}\text { Organism dry weight* } \\ (\mathrm{mg} .)\end{array} \\ & \text { Labelled }+ \text { non-labelled } \dagger & \\ \text { Streptococcus } & 0.81 \pm 0.15 & 0.26 \pm 0.12 \\ \text { L-Form } & 0.84 \pm 0.23 & 0.42 \pm 0.12 \\ & \text { Non-labelled +labelled } \dagger & \\ \text { Streptococcus } & 0.11 \pm 0.04 & 0.57 \pm 0.33 \\ \text { L-form } & 0.15 \pm 0.07 & 0.82 \pm 0.28\end{array}$

* Average weight of organisms counted.

$\uparrow$ Radioactive penicillin added followed by non-radioactive penicillin or vice versa. 
and L-form, respectively; 1-methyl-isatin 3-thiosemicarbazone (23 $\mu \mathrm{g} . / \mathrm{ml}$. medium) was only slightly inhibitory for the parent coccus $(9 \%)$ and its L-form (14\%) as compared with DMS-containing controls. Assay of higher concentrations of these agents, and filipin, was not possible because of their insolubility in aqueous media.

Table 2 tabulates the penicillin-binding capacity of Streptococcus pyogenes and its L-form grown in the absence of penicillin for two years, No apparent difference was observed in the affinity of each organism for labelled penicillin on a cell-weight basis.

\section{DISCUSSION}

These studies were closely patterned after those of Shockman \& Lampen (1962) who found that, with the exception of penicillin and cycloserine, several other antibacterial agents were equally effective in inhibiting the growth of Streptococcus faecalis and protoplasts obtained from it, and that ristocetin and bacitracin were inhibitory at relatively small concentrations against both of these organisms. By comparison, the L-form of $S$. pyogenes displayed greater than 300 - and 60 -fold resistance, respectively, towards these two antibiotics as compared with the parent coccus (Table 1). Surprisingly, puromycin, an inhibitor of protein synthesis, caused lysis of this L-form. A similar response had not been observed with $S$. faecalis protoplasts (Dr G. D. Shockman, personal communication).

Bacitracin may either affect cell-wall synthesis (Salton,1960) or cause lysis of the cytoplasmic membrane (Hancock \& Fitz-James, 1964; Snoke \& Cornell, 1965). The data presented in Table 1 illustrates that the effect of bacitracin was an inhibition of wall formation in Streptococcus pyogenes. This is in agreement with similar findings of others with various group A streptococci (Levinson \& Frank, 1955; Ward et al. 1958; Rotta et al. 1965), staphylococci (Krawitt \& Ward, 1963; Williams, 1963; Kagan et al. 1964; Molander et al. 1964) and their respective L-forms. However, bacitracin apparently affected the membranes of $S$. faecalis protoplasts since the protoplast and the parent coccus were both inhibited by equal concentrations $(5 \mu \mathrm{g} . / \mathrm{ml}$. medium) of this antibiotic (Shockman \& Lampen, 1962). This is in agreement with similar findings reported for Bacillus megaterium and derived protoplasts (Hancock \& FitzJames, 1964).

A compilation of the results from two such serologically distinct streptococci as Streptococcus faecalis and $S$. pyogenes shows that they respond similarly to equal concentrations of certain antibiotics (puromycin, bacitracin, ristocetin). However, the fact that their wall-less derivatives required marked quantitative differences to obtain comparable responses, tempts the speculation of a membrane difference between protoplasts and L-forms after conversion from their respective parental streptococci. This is in accord with our findings that major fatty acid (Panos et al. 1966) and lipid (Cohen \& Panos, 1966) differences and enzymic alterations (Panos \& Cohen, 1966) also were shown in membranes from an L-form and from protoplasts derived from $S$. pyogenes. James, Hill \& Maxted (1965) found other biochemical differences between protoplast membranes and L-form envelopes derived from $S$. pyogenes no. 416 . Thus, it would appear that membrane differences may exist in biological derivatives from taxonomically diverse as well as within related streptococci.

To our knowledge, the present penicillin binding investigations represent the first 
comparative study of a bacterium and its stable L-form. They illustrate that $(a)$ the amount of penicillin bound by Streptococcus pyogenes is in close agreement with that found by others for Gram-positive bacteria; $(b)$ there is no apparent difference in the binding capacity of $S$. pyogenes and its L-form for penicillin despite loss of wall synthesis in the latter; $(c)$ that the binding mechanism for penicillin in these two organisms is probably distinct from that concerned with wall formation.

The authors express their appreciation to Dr G. D. Shockman (Temple University Medical School) for a generous supply of most of the antibiotics used and for reading the manuscript of this paper. This investigation was supported by research grants (A10-4495 and A10-4543) from the National Institute of Allergy and Infectious Diseases, U.S. Public Health Service and a contract (NR 103-576) from the Office of Naval Research. One of us (C.P.) is a Senior Career Development Awardee (U.S.P.H. 7-K3-GM-15, 531).

\section{REFERENCES}

Cohen, M. \& Panos, C. (1966). Membrane lipid composition of Streptococcus pyogenes and derived L form. Biochemistry 5, 2385.

HANCOCK, R. \& FITZ-JAMES, P. C. (1964). Some differences in the action of penicillin, bacitracin, and vancomycin on Bacillus megaterium. J. Bact. 87, 1044.

JAMeS, A. M., Hill, M. J. \& MAXTED, W. R. (1965). A comparative study of the bacterial cell wall, protoplast membrane and L-form envelope of Streptococcus pyogenes. Antonie van Leeuwenhoek $31,423$.

KaGAN, B. M., Zolla, S., Busser, R. \& Liepnieks, S. (1964). Sensitivity of coccal and L forms of Staphylococcus aureus to five antibiotics. J. Bact. 88, 630.

KRAWITT, E. L. \& WARD, J. R. (1963). L phase variants related to antibiotic inhibition of cell wall biosynthesis. Proc. Soc. exp. Biol. Med. 114, 629.

LEVINSON, M. L. \& Frank, P. F. (1955). Differentiation of group A from other beta hemolytic streptococci with bacitracin. J. Bact. 69, 284.

Molander, C. W., Kagan, B. M., Weinberger, H. J., Heimlich, E. M. \& Busser, R. J. (1964). Induction by antibiotics and comparative sensitivity of L-phase variants of Staphylococcus aureus. J. Bact. 88, 591.

PANOS, C. (1965). Cellular physiology during logarithmic growth of a streptococcal L-form. J. gen. Microbiol. 39, 131.

PANOS, C. \& BARkulis, S. S. (1959). Streptococcal L forms. I. Effect of osmotic change on viability J. Bact. 78, 247.

PANOS, C. \& CoHEN, M. (1966). Cell wall inhibition in a stable streptococcal L-form. Biochim. biophys. Acta 117, 98.

Panos, C., Cohen, M. \& Fagan, G. (1966). Lipid alterations after cell wall inhibition. Fatty acid content of Streptococcus pyogenes and derived L-form. Biochemistry 5, 1461.

RotTA, J., Karakawa, W. W. \& KRAUSE, R. (1965). Isolation of L forms from group A streptococci exposed to bacitracin. J. Bact. 89, 1581.

Salton, M. R. J. (1960). Microbial Cell Walls. New York. John Wiley and Co.

Shockman, G. D. \& LAMPEN, J. O. (1962). Inhibition by antibiotics of the growth of bacterial and yeast protoplasts. J. Bact. 84, 508 .

SNOKe, J. E. \& CORNell, N. (1965). Protoplast lysis and inhibition of growth of Bacillus licheniformis by bacitracin. J. Bact. 89, 415.

WARD, J. R., MADOFF, S. \& DIENES, L. (1958). In vitro sensitivity of some bacteria, their L-forms and pleuropneumonia-like organisms to antibiotics. Proc. Soc. exp. Biol. Med. 97, 132.

WILliams, R. E. O. (1963). L-forms of Staphylococcus aureus. J. gen. Microbiol. 33, 325. 